\title{
Fraturas de membro superior em hospitais de nível terciário e suas implicações para a saúde pública
}

\author{
Fractures of the higher member in hospitals of tertiary level and its implications for \\ public health
}

Fracturas del miembro superior em hospitales de nível terciario y sus implicaciones para la salud pública

Valéria Botelho ${ }^{1 *}$, Indiry Caroline Ferreira Silva ${ }^{2}$, ljaciá de Carvalho Ribeiro ${ }^{1}$, Ingridy Caroline Ferreira Silva ${ }^{1}$, Thiago Rhangel Gomes Teixeira ${ }^{1}$, Jane Mary de Medeiros Guimarães ${ }^{3}$, Gildásio Daltro'.

\section{RESUMO}

Objetivo: Apresentar uma revisão integrativa dos últimos 10 anos dos principais tipos de fraturas do membro superior tratadas em hospitais de nível terciário e suas implicações à saúde pública. Métodos: Utilizou-se as bases de dados: PubMed, Scientific Electronic Library Online (SCIELO), Coordenação de Aperfeiçoamento de Pessoal de Nível Superior (CAPES) e Biblioteca Virtual em Saúde (BVS) com os descritores: upper limb and fracture and Brazil. Considerou-se artigos publicados no Brasil entre 2009 e 2019 em inglês, espanhol ou português e que caracterizavam: população, etiologia, local da lesão, veículo, local do acidente e desfecho. Resultados: Foram encontrados 344 artigos, sendo 10 selecionados. 0 trauma de membro superior afeta principalmente adultos. Apresenta os acidentes de trânsito como principal etiologia, acometendo mão, punho e dedos. A motocicleta, as vias públicas e as internações são respetivamente, veículo, cenário e desfecho. Considerações finais: $O$ trauma de membro superior é a $2^{\circ}$ maior consequência dos acidentes de trânsito levando as fraturas ósseas e aumento do número de internações e gastos em saúde e previdenciários.

Palavras-chave: Extremidade superior, Fraturas, Brasil.

\begin{abstract}
Objective: To present an integrative review of the last 10 years of the main types of upper limb fractures treated in tertiary-level hospitals and their implications for public health. Methods: The databases: PubMed, Scientific Electronic Library Online (SCIELO), Coordination for the Improvement of Higher Education Personnel (CAPES) and Virtual Health Library (VHL) with the keywords: upper limb and fracture and Brazil. Articles published in Brazil between 2009 and 2019 in English, Spanish or Portuguese were considered and that characterized: population, etiology, injury site, vehicle, accident site and outcome. Results: 344 articles were found, 10 of which were selected. Upper limb trauma affects mainly adults. It presents traffic accidents as the main etiology, affecting the hand, wrist and fingers. The motorcycle, public roads and hospitalizations are, respectively, vehicle, scenery and outcome. Final considerations: Trauma of the upper limb is the 2nd largest consequence of traffic accidents. The resulting bone fractures lead to an increase in hospitalizations and public spending on health.
\end{abstract}

Keywords: Upper extremity, Fractures, Brazil.

1Universidade Federal da Bahia (UFBA), Salvador - BA. *E-mail: valerimalimaufba@gmail.com

${ }^{2}$ Universidade Federal da Bahia (UFBA), Vitória da Conquista - BA.

3Universidade Federal do Sul da Bahia (UFSB), Itabuna - BA. 


\section{RESUMEN}

Objetivo: Presentar una revisión integradora de los últimos 10 años de los principales tipos de fracturas de extremidades superiores tratadas en hospitales de nivel terciario y sus implicaciones para la salud pública. Métodos: Las bases de datos: PubMed, Scientific Electronic Library Online (SCIELO), Coordinación para el Mejoramiento del Personal de Educación Superior (CAPES) y la Biblioteca Virtual en Salud (BVS) con las palabras clave: extremidad superior y fractura y Brasil. Se consideraron los artículos publicados en Brasil entre 2009 y 2019 en inglés, español o portugués y que caracterizaron: población, etiología, sitio de la lesión, vehículo, sitio del accidente y resultado. Resultados: Se encontraron 344 artículos, de los cuales se seleccionaron 10. El trauma de la extremidad superior afecta principalmente a adultos. Presenta los accidentes de tránsito como la principal etiología, afectando la mano, la muñeca y los dedos. La motocicleta, las vías públicas y las hospitalizaciones son, respectivamente, vehículo, escenario y resultado. Consideraciones finales: El trauma de la extremidad superior es la segunda consecuencia más grande de los accidentes de tránsito. Las fracturas óseas resultantes conducen a un aumento en las hospitalizaciones y el gasto público en salud.

Palabras clave: Extremidad superior, Fracturas, Brasil.

\section{INTRODUÇÃO}

Trauma pode ser definido como uma doença que apresenta um hospedeiro (o doente) e um vetor de transmissão como o automóvel, a arma de fogo entre outros (ATLS, 2012). Corresponde a principal causa de morte em pessoas com menos de 65 anos e ao se avaliar os Anos Potenciais de Vida Perdidos, o trauma é a mais importante causa em relação a neoplasias malignas, doenças cardíacas e doenças cerebrovasculares (STINNER D e DAFYDD E, 2017).

Os casos de Trauma representam a maior parcela dos atendimentos realizados nos hospitais sendo considerado um grave problema de saúde pública. Nos Estados Unidos da América (EUA) são gastos por ano cerca de 400 bilhões de dólares no tratamento de vítimas de trauma. Essas incluem despesas relacionadas à hospitalização, gestão de seguros, custos trabalhistas e redução de produtividade levando a impactos econômicos e sociais (WORLD HEALTH ORGANIZATION, 2009).

As causas externas, segundo a Organização Mundial da Saúde (OMS), podem ser classificadas em acidentais como: quedas, envenenamentos, afogamento, acidentes de trânsito e trabalho, entre outros. $E$ intencionais, que englobam as agressões, lesões autoprovocadas, homicídios e suicídios (LEMOS CA, et al., 2013).

Segundo a OMS e os Centros de Controle e Prevenção de Doenças (CDC), o trauma ou a violência são responsáveis por 9 mortes a cada 60 segundos. A cada ano, ocorrem 5,8 milhões de mortes, o que representa $12 \%$ dos gastos com doenças no mundo. Ao se analisar os custos sociais associados ao trauma, observa-se que $20 \%$ estão relacionados a gastos médicos. Os custos sociais devido a perdas de produtividade estão relacionados à incapacidade (45\%) e morte (35\%) (STINNER D e DAFYDD E, 2017).

No Brasil, em 2014, dados estatísticos revelam que nas estradas federais fiscalizadas pela Polícia Rodoviária Federal (PRF), houve cerca de 169.163 acidentes. Cerca de 8227 pessoas perderam a vida e cerca de 100.000 ficaram feridas. Mais de $25 \%$ dos feridos tiveram lesões graves, $4 \%$ dos acidentes foram fatais, $37 \%$ das vítimas apresentaram ferimentos e $59 \%$ dos acidentes foram sem vítimas (MASSAÚ GC e ROSA RG, 2016).

Segundo dados do Ministério da Saúde, em 2014, mais de 40 mil óbitos foram registrados por acidentes de trânsito e outras 170 mil internações foram contabilizadas no Sistema Único de Saúde (SUS). Entre 2003 e 2012, a Previdência Social gastou $\mathrm{R} \$ 10$ bilhões em auxílio-doença e aposentadoria por invalidez e um total de $\mathrm{R} \$ 15,6$ bilhões em pensões por morte. Estima-se que, no Brasil, o custo total de acidentes de trânsito para a sociedade represente $5 \%$ do Produto Interno Bruto (PIB), o que equivale a $R \$ 295$ bilhões. Desse total, 2,4\% correspondem a custos previdenciários (SPÍNOLA AG, 2015). 
Ao se analisar os custos sociais devido as lesões, cerca de $20 \%$ podem ser atribuídos a custos médicos, $35 \%$ a perdas de produtividade relacionadas à morte e $45 \%$ a incapacidades. Cerca de $85 \%$ das vítimas de trauma contuso têm lesões nos músculos esqueléticos. Em relação às lesões não fatais, $50 \%$ dos custos totais são atribuídos às lesões não fatais nas extremidades, sendo 16\% e 38\% relacionadas às lesões dos membros superiores e inferiores, respectivamente (STINNER D e DAFYDD E, 2017).

Os principais tipos de lesões causadas por acidentes de trânsito incluem: fraturas e luxações de membros e pelve; ferimentos de superfície externa; lesões na medula espinhal; lesão cerebral; lesão ortopédica e lesão neurológica. Verifica-se que as lesões ortopédicas representam a terceira causa mais frequente de hospitalização entre as vítimas de acidentes de trânsito. $E$ cerca de $73 \%$ dos casos afetam a região do membro inferior, principalmente a perna (CRUZ MJA, 2013).

Observa-se também que, entre as vítimas de trauma de energia moderada a alta, apenas 58\% retornaram ao trabalho em 1 ano após sofrerem uma lesão ortopédica classificada em 3 ou mais de acordo com a escala abreviada de lesões (AIS) (STINNER D e DAFYDD E, 2017).

Segundo o Instituto Nacional de Seguridade Social (INSS), em 2017, cerca de 32,83\% dos benefícios por acidentes no Brasil e 8,44\% dos auxílio-doença foram concedidos a vítimas de trauma nos membros superiores (BRAZIL, 2018). Eles comprometem as atividades de desempenho ocupacional nas atividades de vida diária e provocam afastamentos (OLIVEIRA TPO, 2013). Entre as causas mais comuns estão os acidentes de trânsito, acidentes com máquinas, quedas, práticas de atividades de lazer ou decorrentes de violência urbana (BARBOSA RI, et al., 2013).

Devido as repercussões que o trauma apresenta para a sociedade, o objetivo desse estudo é apresentar uma revisão integrativa dos últimos 10 anos sobre os principais tipos de fraturas traumáticas do membro superior atendidas em hospitais de nível terciário no Brasil e suas principais implicações para a Saúde Pública.

\section{MÉTODOS}

Trata-se de uma revisão integrativa, relacionada aos últimos 10 anos sobre os principais tipos de fraturas de membro superior atendidos nos hospitais de nível terciário do Brasil. Optou-se por esta modalidade de pesquisa pela possibilidade de apresentar uma síntese do conhecimento já produzido.

Para a realização do presente estudo foram utilizadas as bases de dados: PubMed, Scientific Electronic Library Online (SCIELO), Coordenação de Aperfeiçoamento de Pessoal de Nível Superior (CAPES) e Biblioteca Virtual em Saúde (BVS) com os seguintes descritores: upper limb and fracture and Brazil. Obtevese inicialmente um total de 837 materiais. O número de artigos encontrados segundo base de dados e as etapas de seleção dos estudos é mostrado abaixo (Tabela 1).

Tabela 1 - Seleção de artigos segundo base de dados.

\begin{tabular}{ccccc}
\hline Base de Dados & Total & 1-Seleção & 20 Seleção & Selecionados \\
\hline PubMed & 54 & 45 & 2 & 1 \\
\hline SCIELO & 731 & 258 & 12 & 8 \\
\hline CAPES & 43 & 35 & 0 & 0 \\
\hline BVS & 9 & 6 & 2 & 1 \\
\hline Total & 837 & 344 & 15 & 10 \\
\hline
\end{tabular}

Fonte: Botelho V, et al., 2020.

Foram considerados artigos publicados entre 2009 e 2019 em língua inglesa, espanhola ou portuguesa, obtendo-se um total de 653 materiais. Foram excluídos estudos estrangeiros, artigos de revisão, metaanálises, dissertações, teses, protocolos, livros, ensaios clínicos e editoriais, obtendo-se ao final 482 artigos.

Todos os artigos foram submetidos a $1^{\circ}$ seleção em que se considerou como critérios de inclusão: somente artigos publicados no Brasil que apresentava como tema fraturas ósseas do membro superior em hospitais ou centros hospitalares de nível terciário e emergências. E critérios de exclusão: artigos que apresentavam dados secundários advindos de banco de dados, obtendo-se um total de 344 artigos. 
Foi realizada uma segunda seleção a partir da leitura de título e resumo de todos os artigos. Após leitura, 15 artigos foram selecionados. Nessa etapa foi adotado como critério de inclusão para o presente estudo: 1) Artigos que descreviam a população acometida, 2) etiologia, 3) local e/ou tipo de lesão de membros superiores, 4) Tipo de veículo no momento do acidente. 5) Local em que ocorreu o trauma ortopédico acidente, 6) Desfechos. Ao final, foram obtidos 10 estudos aptos para a presente revisão integrativa. Todas as etapas de seleção de estudos são mostradas abaixo (Gráfico 1).

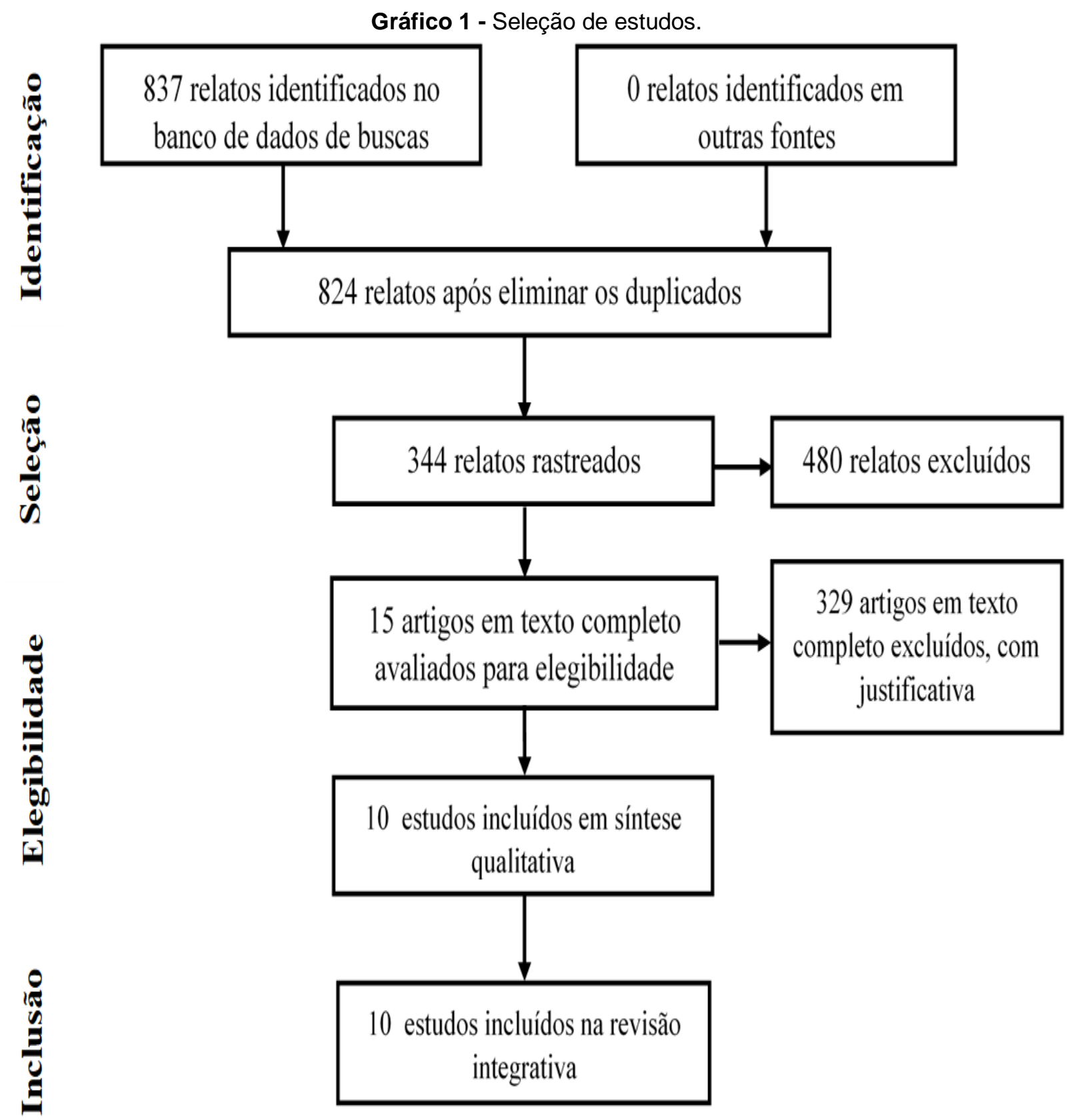

Fonte: Botelho V, et al., 2020.

\section{RESULTADOS}

Os artigos selecionados foram divididos por autor, período de estudo, população, etiologia do trauma, local / tipo de lesão no membro superior, veículo, local do acidente e desfecho. O perfil dos estudos epidemiológicos das fraturas ósseas de membro superior entre 2009 e 2019 em hospitais de nível terciário é mostrado abaixo (Tabela 2). 


\section{Revista Eletrônica Acervo Saúde / Electronic Journal Collection Health | ISSN 2178-2091}

Tabela 2 - Perfil de estudos epidemiológicos entre 2009 e 2019 em hospitais de nível terciário.

\begin{tabular}{|c|c|c|c|c|c|c|c|}
\hline Fonte & Período & População & Etiologia & $\begin{array}{l}\text { Local /Tipo de lesão dos } \\
\text { Membros Superiores }\end{array}$ & Veículo & Local & Desfecho \\
\hline Parreira JG, et al. (2012). & $\begin{array}{l}06.2008 / \\
09.2009\end{array}$ & Adultos & $\begin{array}{l}\text { Acidente de trânsito/ } \\
\text { Atropelamento }\end{array}$ & - & Motocicleta & Via pública & Internação \\
\hline Ladeira RM, et al. (2012). & $2005 / 2009$ & Adolescente & Linha de cerol & Dedos & - & Via pública & Internação \\
\hline $\begin{array}{l}\text { Senefonte FRA, et al. } \\
\text { (2012). }\end{array}$ & $\begin{array}{l}01.2005 / \\
12.2008 .\end{array}$ & Adultos & $\begin{array}{c}\text { Acidente } \\
\text { automobilístico }\end{array}$ & $\begin{array}{c}\text { Fraturas/luxações expostas } \\
\text { Gustilo IIIC. }\end{array}$ & Motocicleta & Via pública & $\begin{array}{c}\text { Amputação de } \\
\text { pododáctilos e } \\
\text { quirodáctilos }\end{array}$ \\
\hline Lemos CA, et al. (2013). & $01.2005 / 07.2005$ & Adultos & Acidente de trânsito/ & $\begin{array}{c}\text { Articulação radiocárpica } \\
\text { /radioulnar }\end{array}$ & Motocicleta & Via pública & Internação \\
\hline Barbosa RI, et al. (2013) & $04.2010 / 04.2011$ & Adultos & Acidente de Moto & Punho e Mão & Motocicleta & Via pública & - \\
\hline Parreira JG, et al. (2013). & $\begin{array}{l}06.2008 / \\
09.2009\end{array}$ & Idosos & $\begin{array}{l}\text { Atropelamento/ } \\
\text { Queda de própria } \\
\text { altura }\end{array}$ & - & - & $\begin{array}{l}\text { Domicílio/ } \\
\text { Via pública }\end{array}$ & $\begin{array}{l}\text { Internação/ } \\
\text { óbito }\end{array}$ \\
\hline $\begin{array}{l}\text { Meschial WC, et al. } \\
\qquad(2014) .\end{array}$ & $2006 / 2008$ & Idosos & Queda & - & - & Domicílio & Internação \\
\hline Batista F, et al (2015). & $\begin{array}{l}01.2007 / \\
12.2013\end{array}$ & Adultos & Acidente de trânsito & Mão & Motocicleta & Via pública & Internação \\
\hline Sousa LRB, et al. (2017). & 01-12.2013 & Adultos & Acidente de trânsito/ & Fratura exposta & Motocicleta & Via pública & Internação \\
\hline Greve JMDA et al. (2018). & $\begin{array}{l}19.02 .2013 / \\
12.05 .2013\end{array}$ & Adultos & Acidente de Trânsito & - & Motocicleta & Via pública & Internação \\
\hline
\end{tabular}

Fonte: Botelho V, et al., 2020. 
Do total de 10 estudos selecionados no período,7 estudos apresentaram como principal população acometida por lesões de membros superiores à de adultos seguido por idosos ( 2 estudos) e adolescentes (1 estudo).

Em relação a etiologia do trauma, 6 estudos apontavam os acidentes de trânsito, seguidos de acidente de trânsito/atropelamento ( 1 estudo), queda ( 1 estudo), atropelamento/queda (1 estudo) e uso de linha de cerol (1 estudo).

Ao se analisar o tipo de veículo utilizado no momento do acidente, 7 estudos indicavam a motocicleta e 3 não referiam o tipo de veículo utilizado. Em relação ao local de ocorrência dos acidentes, 8 estudos descreviam a via pública, 1 o domicílio e 1 apontou domicílio e/ou via pública. Ao se analisar o local de fratura e ou lesões do membro superior, 6 estudos não descreveram, 3 estudos citavam como principais locais: a mão, punho e dedos; e 1 estudo citava a articulação radiocárpica ou radioulnar.

Dos 10 estudos avaliados, 9 apresentavam o desfecho das vítimas de fraturas de membro superior. Os principais desfechos dos estudos avaliados incluíam internação (6 estudos), internação/óbito (1 estudo), amputação de pododáctilos e quirodáctilos (1 estudo), amputação (1 estudo).

\section{DISCUSSÃO}

O membro superior pode ser dividido em suas articulações principais que incluem: complexo do ombro, cotovelo, antebraço, punho e mão. Os traumas ortopédicos se destacam dentre as patologias que acometem esse segmento, podendo interferir na sua função. Entre as consequências que os traumas podem causar estão: dor, redução da mobilidade, fraqueza muscular, instabilidades, além de sequelas permanentes (BARBOSA RI, et al., 2013).

Na revisão integrativa realizada, verifica-se que a principal população acometida por lesões de membros superiores corresponde a de adultos. A principal causa do trauma em adultos apontada foram os acidentes de trânsito, apresentando a motocicleta como principal veículo. A maioria dos acidentes ocorreram em vias públicas. 4 estudos não descreveram o local da fratura ou o tipo de lesão no membro superior. Daqueles que descreveram, um total de 3 , citavam como principais locais a mão, punho e dedos.

A cada hora, em média, cerca de 20 pessoas entram em um hospital público com uma lesão grave resultante de um acidente de transporte terrestre. O total de vítimas graves de trânsito nos últimos dez anos corresponde a 1.636 .878 indivíduos. Cerca de $60 \%$ desses casos envolveram vítimas com idade entre 15 a 39 anos, 8,2\% envolviam a faixa etária de zero a 14 anos e 8,4\% envolveram pessoas acima de 60 anos e quase $80 \%$ das vítimas eram do sexo masculino (CONSELHO FEDERAL DE MEDICINA, 2019).

O aumento no número dos acidentes de trânsito pode ser associado a rápida motorização brasileira e ao baixo nível educacional da população. Devido ao nível educacional, a capacidade em se interpretar as informações sobre os riscos em se conduzir uma motocicleta pode ser prejudicada. Além disso, devido a propaganda vigente em que a motocicleta é associada a liberdade e o silencio da indústria sobre segurança dos veículos, conduz ao aumento da aquisição de motocicletas (VASCONCELLOS EA, 2008).

Em 2011, no Brasil foi registrado recorde na fabricação e venda de motocicletas com destaque para a região Nordeste. As motocicletas representam veículos econômicos, ágeis e que apresentam tamanho e custo reduzido sendo adquiridos com facilidade pela população jovem além de proporcionar acesso rápido e ágil no trânsito do País. Apesar de seus benefícios, há grandes riscos para a população. Verifica-se que ao se analisar o tipo de veículo utilizado durante o acidente de trânsito, observa-se que a probabilidade de uma pessoa sofrer lesões no trânsito utilizando a motocicleta no momento do acidente é trinta vezes maior do que se estivesse conduzindo um automóvel e cerca de noventa vezes mais elevado se estivesse utilizando o ônibus (CORGOZINHO MM, et al., 2019).

Ao se analisar a vulnerabilidade no trânsito e considerando a América com exceção dos Estados Unidos da América (EUA), verifica-se que os pedestres, seguidos dos motociclistas e ciclistas são os mais vulneráveis (WORLD HEALTH ORGANIZATION, 2013). Porém, a realidade brasileira é bem diferente e os motociclistas assumem o maior risco (MELLO JMHP, 2012). 
Os acidentes de trânsito representam altos custos para a sociedade. Imprudência no trânsito, desatenção, embriaguez, entre outros fatores, levam ao aumento das estatísticas de acidentes no Brasil e no mundo. A OMS reconhece os acidentes de trânsito como um grave problema de saúde pública, sendo uma das principais causas de morte e lesões no mundo (OLIVEIRA AMF, 2016).

No Brasil entre 1999 e 2013, houve aumento no número de automóveis e motocicletas. Porém sem investimento adequado em infraestrutura e industrialização, cresceram também os problemas sociais que se expressam com o aumento dos acidentes de trânsito e violência. Além disso, cresceram também os gastos em saúde revelados pelo aumento no número de internações, o grande impacto social devido as sequelas, óbitos e a necessidade de aumento de instalações e leitos em Unidades de Terapia Intensiva (UTIs) (LENTSCK MH, et al., 2019).

Estudos revelam que desde 2009, aumentou o número de acidentes de trânsito de 19 para 23,4 a cada 100 mil habitantes. O País, passou a apresentar o maior recorde em número de mortes no trânsito da América do Sul, e em 2013, cerca de 41 mil pessoas perderam a vida nas estradas brasileiras (WORLD HEALTH ORGANIZATION, 2015).

De acordo o Instituto de Pesquisa Econômica e Aplicada (IPEA) em 2015, verificou-se aumento de $50,3 \%$ nos acidentes de trânsito em rodovias federais, com adição de cerca de $34,5 \%$ nos óbitos e $50 \%$ nos feridos. Esse aumento é associado à crescente urbanização, o aumento no número de veículos e a elevação dos acidentes de trânsito (IPEA,2015). Muitos estudos relatam que a população mais vulnerável é composta por jovens na faixa etária produtiva com alta morbimortalidade e lesões incapacitantes, o que eleva os custos do SUS e a perda de parcela significante da população economicamente ativa (CORGOZINHO MM, et al., 2019).

Segundo o Relatório da Situação de Segurança do trânsito lançado pela OMS em 2018, o número anual de mortes no trânsito chega a 1,35 milhões. O trauma é a principal causa de morte na população entre 5 a 29 anos. Estima-se que até 2030 um total de 2,4 milhões de pessoas devam perder a vida devido acidentes de trânsito e um total de 20 a 50 milhões de indivíduos devam sobreviver, porém com lesões e sequelas de trauma (WORLD HEALTH ORGANIZATION, 2018).

Um estudo realizado na cidade de São Paulo entre 2011 e 2013 sobre acidentes de trânsito, revelou que $52,1 \%$ dos acidentes envolviam motocicletas, atingiam principalmente homens $(81,6 \%)$ na faixa etária de 20 a 29 anos. O trauma do membro superior representou a segunda maior consequência dos acidentes (RODRIGUES CL, et al., 2014). Em 2013, as causas externas foram responsáveis por 151.683 mortes no Brasil, ocupando o terceiro lugar entre as principais causas de morte em adultos (ABREU DROM, 2018).

Os acidentes rodoviários no Brasil representam a causa direta de custos elevados demandados pelo SUS devido a necessidade de atendimento e tratamentos prolongados. Os gastos envolvidos incluem 0 resgate de vítimas, o tratamento dos feridos e a permanência das vítimas durante as internações (MASSAÚ GC e ROSA RG, 2016).

Observa-se ainda que dos estudos avaliados, a segunda população mais afetada era constituída por idosos. A principal etiologia do trauma de membros superiores era representada por queda de própria altura e ocorria geralmente em domicílio ou em vias públicas ou mesmo devido ao atropelamento.

As quedas podem ser definidas como um evento acidental resultante da mudança da posição do indivíduo para um nível inferior ao inicial. São consideradas um importante determinante da saúde do idoso, sendo classificada como causa externa segundo a $10^{\underline{a}}$ Revisão da Classificação Internacional de Doenças (CID-10). Essas são apontadas como importante causa de incapacidade, além de lesões e morte em idosos (MESCHIAL WC, et al., 2014).

Entre os principais fatores de risco relacionados às quedas em idosos estão: sexo feminino, idade avançada, tontura, uso contínuo de medicamentos variados, declínio cognitivo, presença de doenças crônicas, pior desempenho físico, histórico de quedas, ambientes com superfícies escorregadias e de iluminação insuficiente (NASCIMENTO JS e TAVARES DMS, 2016). 
No Mundo, as quedas representam a segunda principal causa de mortes acidentais ou não intencionais. Por ano, cerca de 646.000 mortes são registradas devido a quedas e desse total, mais de $80 \%$ ocorrem em países de baixa e média renda. Os Adultos com idade maior que 65 anos sofrem as quedas mais fatais e, por ano, um total de 37,3 milhões de quedas exigem atenção médica (WORLD HEALTH ORGANIZATION, 2018).

Um estudo realizado em 23 estados brasileiros com 6.616 idosos, mostrou que a prevalência de quedas foi de $27,6 \%$ e desses $11 \%$ resultaram em fratura. A prevalência de quedas por região geográfica variou de $18,6 \%$ no Norte a $30 \%$ no Sudeste (SIQUEIRA FV, et al., 2011).

Verifica-se que os pacientes idosos apresentam maior taxa de mortalidade do que os jovens após trauma. Ainda não há consenso sobre os reais motivos da maior probabilidade de morte nesse grupo, porém, alguns fatores estão relacionados como a gravidade do trauma, doenças preexistentes e reserva fisiológica. Estudos apontam ainda, que à longo prazo, o trauma exerce também efeito na sobrevida do idoso em cerca de 3 a 5 anos após o evento quando comparado a idosos que não sofreram injuria e a causa desse possível efeito ainda é desconhecida (SOUZA JAG e IGLESIAS ACRG, 2002).

$\mathrm{Na}$ presente revisão integrativa realizada, constatou-se que apenas um estudo, o de Ladeira RM, et.al. (2012); apresentou como principal população acometida por lesões de membros superiores, os adolescentes na faixa etária de 15 anos. O principal mecanismo apontado no estudo foi o da utilização da linha de cerol, uma mistura de vidro e cola utilizada por crianças e adolescentes durante atividades recreativas conhecida como "batalha da pipa". Verifica-se que são poucos os estudos que analisam as lesões provocadas pela linha de cerol, prática recreativa que pode trazer sérias consequências como as apontadas no estudo que envolve o corte e amputação de dedos.

É observado ainda, que essa prática pode provocar quedas, descargas elétricas, agressões e acidentes de trânsito, além de lesões sérias em face e pescoço principalmente de motociclistas e ciclistas, principais atingidos. Em alguns casos, a depender da região acometida pode resultar ainda em lesões fatais.

Do total de 10 estudos avaliados, 8 apontavam a internação como desfecho principal. Estudo conduzido por Senefonte FRA, et al. (2012); relatava a amputação de pododáctilos e quirodáctilos e estudo realizado por Barbosa RI, et al. (2013); não descrevia o tipo de desfecho das vítimas de trauma de membros superiores.

Verifica-se que as internações hospitalares são responsáveis por grandes gastos ao sistema de saúde brasileiro. Em 2013, o SUS financiou um total de 170.805 internações devido a Acidente de Transporte Terrestre (ATT) com taxa de 85 a cada 100 mil habitantes e gasto total de $\mathrm{R} \$ 231.469 .333,13$.

Ao se avaliar o tempo de hospitalização observado foi de 1.072 .557 dias com média de 6,3 dias de internação por paciente. Ao se analisar o perfil de pacientes internados, verificou-se que a maioria envolvia pacientes do sexo masculino (78,2\%). A faixa etária mais acometida era constituída de indivíduos com idade entre 20 e 39 anos. Destaca-se que 51,9\% dos indivíduos internados estavam em acidentes que envolvia motocicletas (CONSELHO FEDERAL DE MEDICINA,2019).

Acrescenta-se ainda que além dos custos sobre o sistema de saúde do País, há grandes gastos com a incapacidade funcional e pensões por morte devido ao Trauma. Em 2015, por exemplo, foram gastos cerca de $\mathrm{R} \$ 10$ bilhões pela Previdência Social em auxílios-doença e aposentadorias por invalidez e um total de $\mathrm{R} \$ 15,6$ bilhões em pensões por morte (SPÍNOLA AG,2015). Esses dados revelam os aspectos econômicos envolvidos no trauma e que ainda se destaca na realidade brasileira.

Verifica-se ainda que entre 2009 e 2018, houve crescimento de 33\% no número de internações no Brasil (CONSELHO FEDERAL DE MEDICINA, 2019). Esse fato mostra a necessidade de conscientização e políticas mais efetivas para a prevenção de acidentes e segurança na sociedade (CONSELHO FEDERAL DE MEDICINA, 2019). Assim, as fraturas de membro superiores podem provocar lesões transitórias ou permanentes com impacto direto na sociedade aumentando os gastos econômicos, de saúde e previdenciários, além de trazer repercussões biopsicossociais para o indivíduo acometido e a família e muitas vezes, a depender do tipo de trauma, resultar em morte. 


\section{CONSIDERAÇÕES FINAIS}

A população adulta é a principal vítima de acidentes no trânsito relacionados a utilização de motocicletas. As lesões dos membros superiores mais descritas nos estudos avaliados envolvem a mão, punho e dedos. Nos idosos, a etiologia principal são as quedas apontadas como principal causa de lesões, internamento e aumento da mortalidade nessa faixa etária. A maioria dos desfechos relatados envolvem as internações que provocam aumento dos gastos do Sistema Único de Saúde e da Previdência Social, além de reduzir a produtividade da população economicamente ativa. Acrescenta-se ainda, que os traumas de membros superiores podem provocar incapacidade laborativa transitória ou permanente e trazer repercussões psicossociais e econômicas para as vítimas e família. Além do aumento da mortalidade principalmente na faixa etária ativa da população e do número de Anos de Vida Perdidos. Esse trabalho contribui com o conhecimento e atualização do panorama epidemiológico do trauma ortopédico nos diferentes cenários dos grandes serviços de saúde do Brasil. Além de permitir a organização de estratégias de saúde pública para prevenção e atendimento dos diferentes tipos de fraturas de membro superior segundo faixa etária.

\section{REFERÊNCIAS}

1. ABREU DROM, et al. Internação e mortalidade por quedas em idosos no Brasil: análise de tendência. Ciência \& Saúde Coletiva, 2018; 23(4): 1131-1141.

2. ANDRADE SSCA, JORGE MHPM. Internações hospitalares por lesões decorrentes de acidente de transporte terrestre no Brasil: permanência e gastos. Epidemiologia e Serviços de Saúde,2013; 26(1): 31-38.

3. ATLS. Advanced Trauma Life Support. Suporte Avançado de Vida no Trauma. Manual de Alunos. 9e ed, American College of Surgeons, Chicago, 2012.

4. BARBOSA RI, et al. Perfil dos pacientes com lesões traumáticas do membro superior atendidos pela fisioterapia em hospital do nível terciário. Acta Fisiátrica, 2013; 1 (1): 14-19.

5. BATISTA F, et al. Perfil epidemiológico das fraturas de extremidade em acidentados com motocicleta. ACTA Ortopédica Brasileira, 2015; 23 (1): 43-46.

6. BRASIL. Ministério da Economia. Dados abertos da previdência social - Tabelas do Anuário Estatístico da Previdência Social. Brasília: Instituto Nacional do Seguro Social, 2018.

7. CORGOZINHO MM, et al. Vulnerabilidade sobre duas rodas: tendência e perfil demográfico da mortalidade decorrente da violência no trânsito motociclístico no Brasil, 2004-2014, Caderno de Saúde Coletiva, 2018 ; 26 (1): $92-$ 99.

8. CONSELHO FEDERAL DE MEDICINA, 2019. Em dez anos, acidentes de trânsito consomem quase R $\$ 3$ bilhões do SUS. Brasília: CFM;2019. Disponível em< http://portal.cfm.org.br/index.php?option=com_ content\&vie W=article\&id=28254:2019-05-22. Acesso em 23 de março de 2020.

9. FERNANDES ALC. A influência das condições de vida na capacidade do cumprimento das medidas socioeducativas em meio aberto: o caso da FUNPAPA (Belém-2011). Dissertação (Mestrado em Desenvolvimento e Meio Ambiente Urbano) - Pró-reitora de pós-graduação, pesquisa e extensão - PPPE. Núcleo de estudos e pesquisa em qualidade de vida e meio ambiente. Universidade da Amazônia - UNAMA. Belém, 2013, 104p.

10. GREVE JMDA, et al. Fatores relacionados aos acidentes de moto com vítimas: Estudo epidemiológico. MedicalExpress, 2018; 5: mo18007.

11. IPEA, Instituto de Pesquisa Econômica Aplicada. Acidentes de trânsito nas rodovias federais brasileiras: caracterização, tendências e custos para a sociedade. Brasília, DF, 2015; 42p.

12. LADEIRA RM, et al. Epidemiologia dos acidentes provocados por linhas com cerol: estudo de vítimas atendidas em hospital de trauma em Belo Horizonte, Brasil. Revista Brasileira de Epidemiologia, 2012; 15(2): 407-414.

13. LEMOS CA, et al. Perfil de vítimas e tratamento de lesões por causas externas segundo atendimento pelo Centro de Reabilitação Municipal de Uberlândia, MG - Causas externas e fisioterapia. Revista Brasileira de Epidemiologia, 2013; 16(2): 482-492.

14. LENTSCK MH, et al. Panorama epidemiológico de dezoito anos de internações por trauma em UTI no Brasil. Revista de Saúde Pública, 2019; 53: 83.

15. MASSAÚ GC, ROSA RG. Acidentes de trânsito e direito à saúde: prevenção de vidas e economia pública. Artigo Original. Revista: Direito Sanitário, 2016; 17 (2): 30-47.

16. MELLO JMHP. Mortes de motociclistas ultrapassam as de pedestres no Brasil. Revista Abramet. 2012; 29(1):32-35.

17. MESCHIAL WC, et al. Idosos vítimas de quedas atendidos por serviços pré-hospitalares: diferenças de gênero. Revista Brasileira de Epidemiologia, 2014 ;17 (1): 3-16.

18. NASCIMENTO JS, TAVARES DMS. Prevalência e fatores associados a quedas em idosos. Texto contexto enfermagem, 2016; 25 (2): e0360015.

19. OLIVEIRA TPO, et al. Estudo retrospectivo dos acidentes traumáticos da mão relacionados ao trabalho. Cadernos de Terapia Ocupacional da UFSCar, 2013; 21 (2): 339-349.

20. OLIVEIRA AMF. ONU -década de ações para a segurança no trânsito 2011-2020. Brasília DF: Câmara dos Deputados, 2016. 
21. PARREIRA JG, et al. Análise comparativa entre as lesões encontradas em motociclistas envolvidos em acidentes de trânsito e vítimas de outros mecanismos de trauma fechado. Revista da Associação Médica Brasileira, 2012; 58(1): 76-81.

22. PARREIRA JG, et al. Análise comparativa das características do trauma entre idosos com idade superior e inferior a 80 anos. Revista do Colégio Brasileiro de Cirurgiões, 2013; 40(4): 269-274.

23. RODRIGUES CL, et al. Acidentes que envolvem motociclistas e ciclistas no município de São Paulo: caracterização e tendências. Revista Brasileira de Ortopedia, 2014; 49 (6): 602-606.

24. SENEFONTE FRA, et al. Amputação primária no trauma: perfil de um hospital da região centro-oeste do Brasil; Jornal Vascular Brasileiro, 2012;11(4), 269-276.

25. SIQUEIRA FV, et al. Prevalência de quedas em idosos no Brasil: uma análise nacional. Caderno de Saúde Pública, $2011 ; 27$ (9): 1819-1826.

26. SOUSA LRB, et al. Notificação do acidente traumático em um hospital público da Amazônia Brasileira. Revista Brasileira em Promoção da Saúde, 2017; 30 (1): 64-71.

27. SOUZA JAG, IGLESIAS ACRG. Trauma no idoso. Revista da Associação Médica Brasileira, $2002 ; 48$ (1): $79-86$.

28. SPÍNOLA, AG. Estudo sobre a questão da saúde e da segurança do trabalho e as implicações para os regimes próprios e o regime geral de previdência social - construção de perfil epidemiológico previdenciário, Fundação de Apoio à Pesquisa, Ensino, Tecnologia e Cultura, Novembro de 2015.

29. STINNER D, DAFYDD E. Surgical Management of Musculoskeletal Trauma. Surgical Clinics of North, 2017; 97(5):1119-1131.

30. VASCONCELLOS EA. O custo social da motocicleta no Brasil. Revista Transportes Públicos, 2008; (30-31):127-142.

31. WORLD HEALTH ORGANIZATION, 2009. In: Global status report on road safety: time for action. Geneva: World Health Organization. Disponível em: www.who.int /violence_injury_prevention/road_safety_status/ 2009.Acesso em: 14 de mar.2020.

32. WORLD HEALTH ORGANIZATION, 2018. In: Global status report on road safety 2018. Geneva: World Health Organization. Disponível em: https://www.who.int/violence_injury_prevention/road_safety_status /20 18/en/. Acesso em: 14 de mar. 2020.

33. WORLD HEALTH ORGANIZATION. Global Status Report on Road Safety 2013: supporting a decade of action, 2011-2020. 1 nd ed. Switzerland: WHO, 2013, 318p.

34. WORLD HEALTH ORGANIZATION, 2018. In: Falls. Geneva: World Health Organization Disponível em: https://www.who.int/en/news-room/fact-sheets/detail/falls. Acesso em: 20 de mar de 2020. 